\title{
Analysis of Paddy straw, Paddy Husk and Saw Dust Briquettes by using Hand Operated Briquetting Machine
}

\author{
Nitesh A. Pachpor ${ }^{1 *}$, Priti P. Lad ${ }^{1}$, Ganesh S. Bhatane ${ }^{2}$, \\ Saurabh S. Bajare ${ }^{2}$ and Ramesh J. Pilghar ${ }^{2}$
}

${ }^{1}$ Department of Renewable Energy Technology, ${ }^{2}$ Department of Agriculture Process Engineering, College of Agriculture Engineering and Technology, Saralgaon, India

*Corresponding author

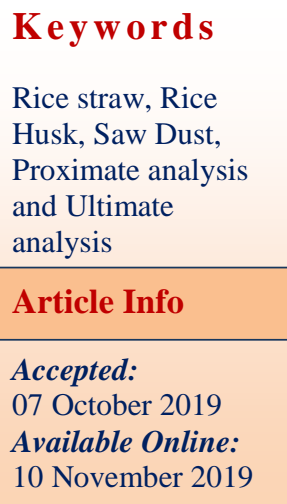

\section{Introduction}

The overall pollution in the world is increasing day by day and the major contribution to this pollution is the use of fossil fuels, hence there is huge push to reduce the usage of fossil fuels and to look for the alternative biomass fuel. Developing countries are facing huge problem with waste management and agro residues such 
as coir pitch, dry leaves, rice husk, coffee husk etc., are contributing majorly to this problem. We usually see these agro residues and saw mill residues are usually burnt on roadside or dump yards, which again results in pollution. There is a need to find a way so that these agro residues and saw mill residues can be converted into fuels. However, these residues are very difficult to transport, handle, store and if these residues are burnt directly it results in very poor thermal efficiency and may create lot of air pollution. These kinds of problems can be avoided by briquetting the waste biomass in to usable energy generating fuel. Hence, if proper efforts are made biomass briquettes will become an alternative for some of the fossil fuels to a greater extent and briquetting of agro residues will help in waste management and reduced air pollution. Biomass briquetting is the densification of loose agro residues, saw mill residues with or without binding agents to produce compact solid composites of different sizes with the application of pressure. The end use of briquettes is mainly for replacing coal in industry for heat applications (steam generation, melting metals, space heating, brick kilns, tea curing, etc) and power generation through gasification of biomass briquettes and for domestic uses.

Biomass is an energy organic matter, especially plant matter that can be converted to fuel and is therefore regarded as potential energy sources.

Now a day's briquetting technology plays an important role in the utilization of -agrowastes for higher calorific value and highenergy utilization. In this study, a briquetting process will aim to investigate production of an alternate eco-friendly fuel. Rajasthan has major contribution towards yellow revolution in the country. Rajasthan is having large production capacity of mustard with large amount of waste after harvesting.

The calorific value of biomass is high and finally used as fuel for cooking at domestic level or it is burnt on farm as it causes spoilage and disposal problem all over the year. The use of mustard stalk waste for production of briquette improves the net calorific value per unit volume and also helps to reduce deforestation by providing a substitute for fuel wood as well as conventional fuel. The technology of briquetting is defined as the densification process for improving the biomass fuel characteristics.

It is proposed to develop an efficient briquetting machine capable to produce briquettes of biomass that can be used as eco-friendly fuel for cooking in chulhas as well as for gasification to produce electricity. It has also potential to sale directly in market for use in boilers. It is worth mentioning that briquetting technology in India has not yet reached at maturity stage and there is considerable scope for design improvements, leading to increased reliability and reduced energy consumption for the briquetting of agricultural residues. Also, the direct burning of loose agro waste residues like rice husk, paddy straw, palm kernel shells, groundnut shells in conventional manner is associated with very low thermal efficiency, loss of fuel and widespread air pollution. When compressed into briquettes, these problems are mitigated, transportation and storage cost are reduced and energy production by improving their net calorific value per unit is enhanced (Grover et al., 1996). This work is focussed on the Preliminary Production of Briquettes from biomass and cow dung. 


\section{Materials and Methods}

The experiment was carried out at Department of Electrical And Other Energy Sources, College of Agricultural Engineering and Technology, Saralgaon. The plan of research work had been briefed here. The methodology followed during the course of this research work was discussed in brief under this chapter. The following methodology was adopted.

\section{Experimental site}

An experimental set up of pellet briquetting system installed by the College of agril. Engg. And Tech., Saralgaon, Department of Electrical and Other Energy Sources.

\section{Climatic condition}

Saralgaon, the place of investigation comes under the Maharashtra plane sub humid area of the state. The mean annual rainfall 1400 $\mathrm{mm}$ out of which $85 \%$ is received between the middle of June to October.

The maximum temperature during the summer month reaches high $48^{\circ} \mathrm{C}$ and minimum goes to $20 \mathrm{C}$ during the winter months. The relative humidity is high from June to October and shows a declining trend thereafter with an absolute minimum during peak winter (January).

\section{About the briquetting machine}

It is designed to produce briquettes of 79 $\mathrm{mm}$ diameter and $32 \mathrm{~mm}$ thickness and $25 \mathrm{~mm}$ diameter passing through the central axis of the briquette length. The goal in this design is to design an efficient briquetting machine capable of compacting biomass by applying pressure. The machine will be manually operated. The design will be transportable, storable (Table 1 and Fig. 1).

\section{Biomass briquette production}

\section{Raw material used}

\section{Rice straw}

Rice Straw on a one of the abundant lignocelluloses crop residue in the world and in India. It is a major field residue, this is energy input, given the high fuel price and the great demand for reducing green house gas emissions as well as air pollution rice straw is rarely use as source of renewable energy (Fig. 2).

\section{Rice husk}

Rice husk is the hard and protective shell covering over the rice kernel. For every tones of polished rice, $280-300 \mathrm{~kg}$ of rice husk is produced. It has medium calorific value and high ash content. Silica crested tubular structural composition of husk prevents uniform and complete burning of these material in high percentage of residual carbon in the ash obtained in common furnance like the step grate furnace (Fig. 3).

\section{Saw dust}

Saw Dust is the composed of fine particle of wood. This material is producing from cutting wood with a saw, hence its name. The particle size ranges from $0.3-0.6 \mathrm{~mm}$. The calorific value of saw dust as a raw material is about $3600 \mathrm{kcal} / \mathrm{kg}$ (Fig. 4).

\section{Binder materials}

\section{Cow dung}

Cow dung is itself a good fuel when dried in the sun. It can be used as a binde material along with the raw materials. It is a sticky in nature and is recommended to use as binder in proportions ranging from $50-85 \%$ with the 
raw material. The calorific value of fuel can be increased by using the cow dung as its calorific value is also higher (Fig. 5)

\section{Mixing with binder}

The binding material is used for strengthening the briquettes. The rice straw is mixed with binder. Cow dung was used as binding material, the various combination of measure constituents were tried in order to get briquettes of the desired quality. The different combination $\mathrm{B} 1$ rice straw and cow dung as (10:40), B2 rice husk, rice straw and cow dung (10:05:40) and B3 saw dust, rice straw and cow dung as (20:05:40) by weight was used for briquette production. The measure quality of water was added in mixture using thumb rule for that the material should get bind by hand pressing after addition of water.

\section{Briquetting production}

The rice straw, rice husk ad saw dusts were used as major constitutes for briquetting with cow dung as a biding material. For the production of briquettes; hand operated machine was use source of power. The material was push forward due to geometry of piston.

\section{Machines use}

\section{Hot air oven}

Hot air ovens are electrical devices which use dry heat to sterilize. They were originally developed by Pasteur. Generally, they use a thermostat to control the temperature. Their double walled insulation keeps the heat in and conserves energy, the inner layer being a poor conductor and outer layer being metallic (Fig. 6).

\section{Muffle furnace}

A muffle furnace is a furnace with an externally heated chamber, the walls of which radiantly heat the contents of the chamber, so that the material being heated has no contact with the flame (Fig. 7).

\section{Theoretical consideration}

\section{Physical ad thermal analysis of briquettes}

\section{Density}

The briquettes are randomly selected for each production batch for evolution of physical properties. The mean compressed densities of the briquettes were determined immediately after removal from the machine as a ratio of measured weight to calculated volume.

The weight of produce briquettes were determined using digital weighing balance. The diameters and length of the briquettes were taken directly by measuring with digital Vernier caliper the volume of the cylindrical shaped briquettes was then determined. Then the density was determined for each briquette as ratio of briquettes weight to volume.

\section{Formula}

Density $\left(\mathrm{g} / \mathrm{cm}^{3}\right)=\frac{\text { weight of briquettes in grams }}{\text { volume of briquettes in } \mathrm{cm} 3}$

Combustion characteristic of biomass briquettes

\section{Proximate analysis}

\section{Volatile matter}

The percentage volatile matter was determined by pulverizing $2.25 \mathrm{~g}$ of the briquette sample in a crucible and placing in an oven unit a constant weight was obtained.

The briquette was then kept in a furnace at a temp. of $550^{\circ} \mathrm{C}$ for $10 \mathrm{~min}$ weighed after cooling in a desiccators. The PVMA was calculated using equation below 
$\mathrm{VM}(\%)=\frac{A-B}{A} \times 100$

Where,

A is the weight of the oven dried sample ( $\mathrm{g}$ )

$\mathrm{B}$ is the weight of the sample after $10 \mathrm{~min}$ in the furnace at $550 \mathrm{C}(\mathrm{g})$

\section{Ash content}

The percentage ash content (PAC) was also determined by heating $2.25 \mathrm{~g}$ of the briquette sample in the furnace at temp of $550 \mathrm{C}$ for $4 \mathrm{~h}$ and weight after cooling in a decicator to obtained the weight of ash (C). The PAC was determined using equation below

$\mathrm{AC}(\%)=\frac{C}{A} \times 100$

\section{Moisture content}

The percentage moisture content (PMC) was found by weighing $2.25 \mathrm{~g}$ of the briquette sample (E) and oven drying it at $105 \mathrm{C}$ until the mass of the sample was constant. The change in weight (D) after 60 min was used to determine the samples PMS using the equation below

$\operatorname{MC}(\%)=\frac{w-d}{w} \times 100$

\section{Fixed carbon percentage}

The fixed carbon (FC) indicates the heating value of the biomass. This is obtained by subtracting the percentage of moisture, volatile matter and ash content from 100.

$\mathrm{FC}(\%)=100-(\mathrm{MC}+\mathrm{VM}+\mathrm{AC})$

\section{Calorific value}

The calorific value of briquette was measured by using an oxygen bomb calorimeter. One gm of briquette sample was taken in a nichrome crucible. A $15 \mathrm{~cm}$ long cotton thread was placed over the sample in the crucible to facilitate ignition. Both the electrode of the calorimeter was connected by nichrome fuse wire. Oxygen gas was filled in the bomb calorimeter pressure of around 25 to $30 \mathrm{~atm}$. The water (2 lit) taken in the bucket was continually steered to homogeneous the temp.

The sample was ignited by switching on the current through the fusing wire and the rise in temp of water is automatically recorded. The following formula was used to determine the calorific value of sample.

$(\mathrm{GCV})=(2500-\mathrm{T}) /($ initial wt of sample $)-$ (heat released by cotton thread + heat released by fused wire) $\mathrm{kcal} / \mathrm{kg}$

\section{Ultimate analysis}

It is the process of predicting the chemical composition of briquette such as nitrogen, sulphur, oxygen, hydrogen and carbon. In this the sample is burned in a crucible in a subjecting steam of air oven to convert the sample into carbon dioxide and water.

Gas analysis procedure is used to determine mass friction. And carbon percentage as well as hydrogen percentage is calculated. Once the ash and moisture determined the amount of oxygen can be found out by the difference.

The oxygen percentage of biomass. This is obtained by subtracting the percentages of carbon, hydrogen, nitrogen sulpheur, and ash content from 100

$\mathrm{O}(\%)=100-(\mathrm{C}+\mathrm{H}+\mathrm{N}+\mathrm{S}+\mathrm{Ash})$

\section{Results and Discussion}

The chapter deals with the results and discussion regarding physical, combustion 
properties and proximate analysis, ultimate analysis of the produced biomass briquettes. Cost analysis and machine performance.

\section{Comparison of different ratio of biomass}

It is obvious that, there different ratio of raw material B1- rice straw and cow dung (10:40), $\mathrm{B} 2$ - rice husk, rice straw, cow dung (10:05:40) and B3- saw dust, rice straw, cow dung (20:05:40) was used to produce briquettes have little different in dimension of briquettes. The B3- saw dust, rice straw, cow dung in proportion of $(10: 05: 40)$ produced heavier briquettes as compare to the other two ratio. Dia of briquettes in each case are same. But littlt different in length was observed. Longest briquettes (6.19) are produced with the B3- saw dust, rice straw, and cow dung (20:05:40) followed by the first and second ratio of materials.

\section{Physical properties of produced briquettes}

\section{Density of briquettes}

Density of briquettes was determined for relative compactness, easy to transportation and improves the burning quality of briquettes and also used for increase the combustion properties of obtained density of all briquettes are presented. It is clear that rice straw briquette has more density as compare to other biomass. Average weight of briquettes was found different with the different biomass used. It was found maximum for B3 and minimum for the briquette. Average volume of the briquette was also found different for the each type of briquette because of shrinkage of briquette in diameter, it depend on the moisture content of the biomass. Hence the density of B3, briquettes was found maximum $0.91 \mathrm{~g} / \mathrm{cm}^{3}$, this show that means it is more durable and has higher strength for transportation as well as higher burning time as compare to other biomass briquettes (Table 2).

\section{Moisture content}

Moisture content test was determined for drying of briquettes and used in the loss of chemically bound structural water. It was observed from table 3 that B-3 saw dust, rice straw, and cow dung (20:05:40) briquette content low moisture content $53.64 \%$ which is better for combustion and safer for storage and transportation as compare to the biomass briquettes.

\section{Proximate analysis}

The value of proximate analysis of fuels is important because they give an approximate idea about the energy values and extends of pollutant emission during combustion. The percentage proximate value of the different contents (Fig. 8).

Data recorded that the maximum moisture content $9.77 \%$ was found in B1 briquette and minimum $6.66 \%$ in $\mathrm{B} 3$ briquette as comparison to other biomass. B1 briquette left maximum ash content $(24.44 \%)$ as residue while minimum $(15.00 \%)$ ash content was observed in B3 briquette after combustion.

The optimum volatile matter was found in B1 briquette (64.00\%) and minimum (62.22\%) for B3. The B3 briquette content maximum $(16.12 \%)$ fixed carbon percentage and minimum $(1.35 \%)$ was observed on briquettes.

The higher calorific value was obtained maximum for B3 as $4086 \mathrm{kcal} / \mathrm{kg}$ which emits the high energy as compare to other briquettes and the maximum value was found for B1 as $3356 \mathrm{kcal} / \mathrm{kg}$

\section{Ultimate analysis}

The ultimate analysis indicates the various elemental chemical constituent such as carbon, hydrogen, oxygen, sulphur (Fig. 9). 
Table.1 Specification of briquetting machine

\begin{tabular}{|c|c|c|}
\hline PART & PCS & DESCRIPTION \\
\hline $\mathbf{A}$ & 1 & $\begin{array}{c}\text { Vertical Support } \\
\text { 823mmX 366mm X 76mm }\end{array}$ \\
\hline B & 1 & $\begin{array}{c}\text { Top Spacer } \\
\text { 229mm X 76mm X 3mm }\end{array}$ \\
\hline C & 1 & $\begin{array}{l}\text { Pusher Lever } \\
823 \mathrm{mmX} 25 \mathrm{~mm} \text {, see drawing for end taper }\end{array}$ \\
\hline D & 1 & $\begin{array}{l}\text { Base plate with grooves, see drawing. } \\
\text { mm X397 mm X 91mm, }\end{array}$ \\
\hline $\mathbf{E}$ & 1 & $\begin{array}{c}\text { Front Leg } \\
250 \mathrm{~mm} \mathrm{X} \mathrm{54mm} \mathrm{X} \mathrm{34mm}\end{array}$ \\
\hline G & 1 & $\begin{array}{l}\text { Mold box, } \\
244 \mathrm{~mm} \text { of } 82 \mathrm{~mm} \text { mold dia holes on } 1 \mathrm{~mm} \text { centre }\end{array}$ \\
\hline H & 1 & $\begin{array}{l}\text { Piston, sized to fit inside the } 80 \mathrm{~mm} \\
13 \mathrm{~mm} \text { thick with } 254 \mathrm{~mm} \text { dia hole } 25 \mathrm{~mm} \text { Deep. }\end{array}$ \\
\hline I & 1 & $\begin{array}{l}\text { Center pipe } \\
\text { 609mm long, 56mm dia. }\end{array}$ \\
\hline
\end{tabular}

Table.2 Density of briquettes

\begin{tabular}{|c|c|c|}
\hline Briquettes & $\begin{array}{c}\text { Average Weight of } \\
\text { briquette, } \mathbf{( g m})\end{array}$ & $\begin{array}{c}\text { Average Volume of } \\
\text { briquettes, } \mathbf{( c m}^{\mathbf{3}} \mathbf{)}\end{array}$ \\
\hline B1 & 500 & 28.09 \\
\hline B2 & 450 & 22.77 \\
\hline B3 & 400 & 28.09 \\
\hline
\end{tabular}

Table.3 Proximate analysis of produced briquettes

\begin{tabular}{|c|c|c|c|c|c|c|}
\hline Sr. No & Briquette & \multicolumn{4}{|c|}{ Parameters } \\
\cline { 3 - 7 } & & $\mathrm{MC}(\%)$ & Ash (\%) & $\mathrm{VM}(\%)$ & $\mathrm{FC}(\%)$ & $\mathrm{CV}(\mathrm{kcal} / \mathrm{kg})$ \\
\hline 1. & B1 & 9.77 & 24.44 & 64.44 & 1.35 & 3356 \\
\hline 2. & B2 & 12.00 & 20.00 & 63.00 & 5.00 & 3518 \\
\hline 3. & B3 & 6.66 & 15.00 & 62.22 & 16.12 & 4086 \\
\hline
\end{tabular}


Fig.1 Hand operated piston press briquetting machine

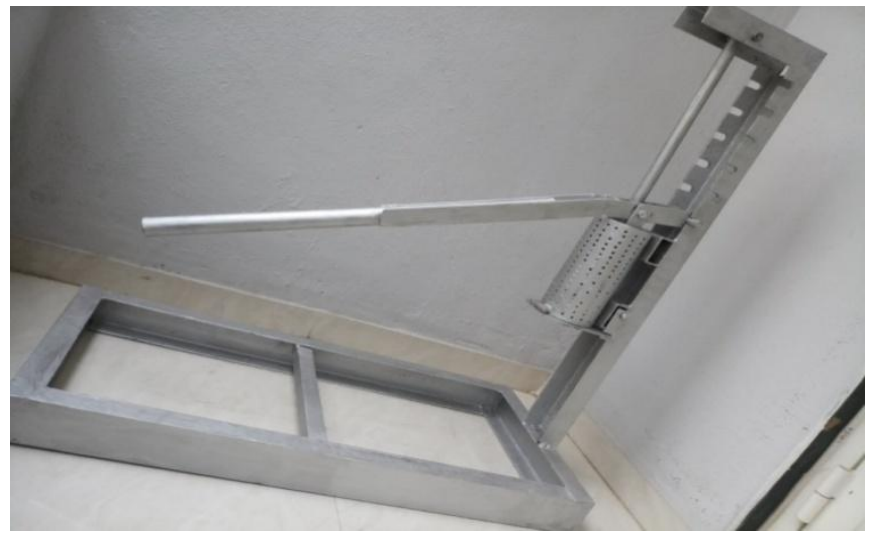

Fig.2 Rice straw

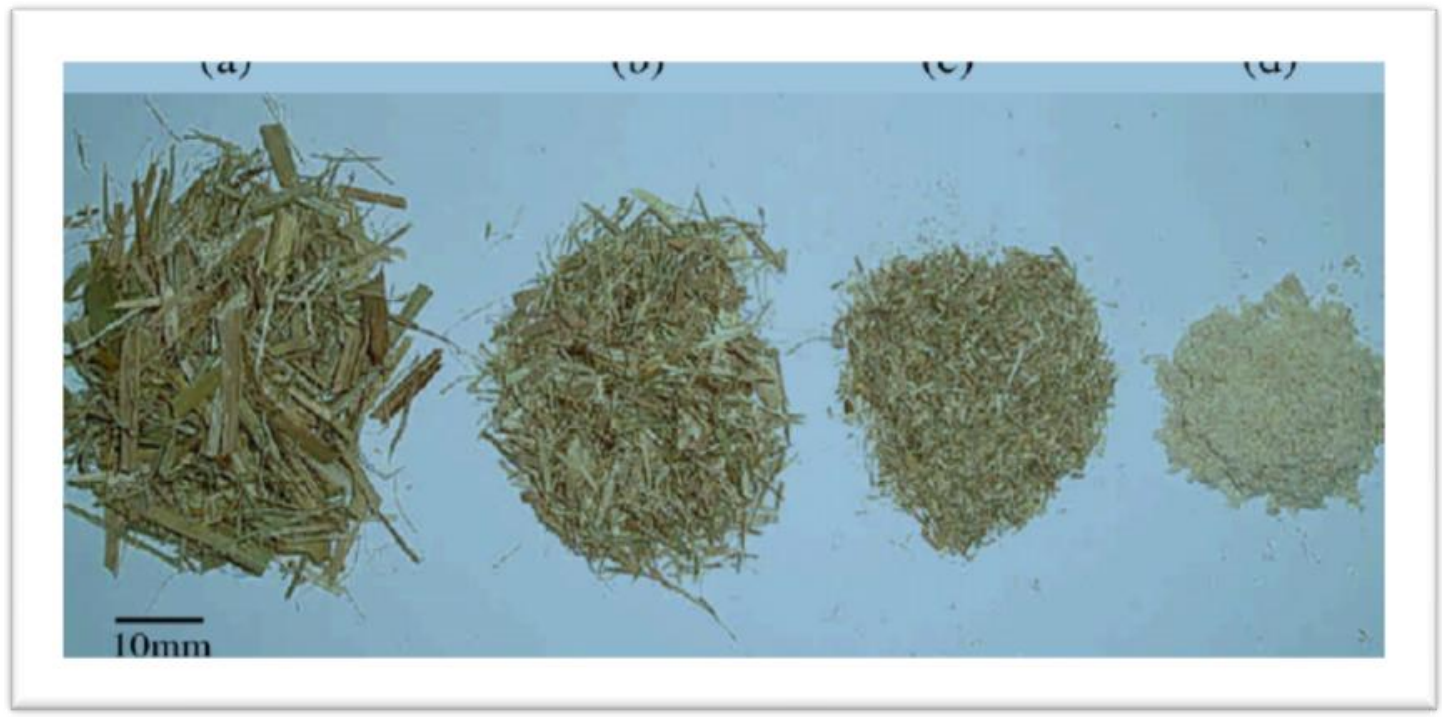

Fig.3 Rice husk

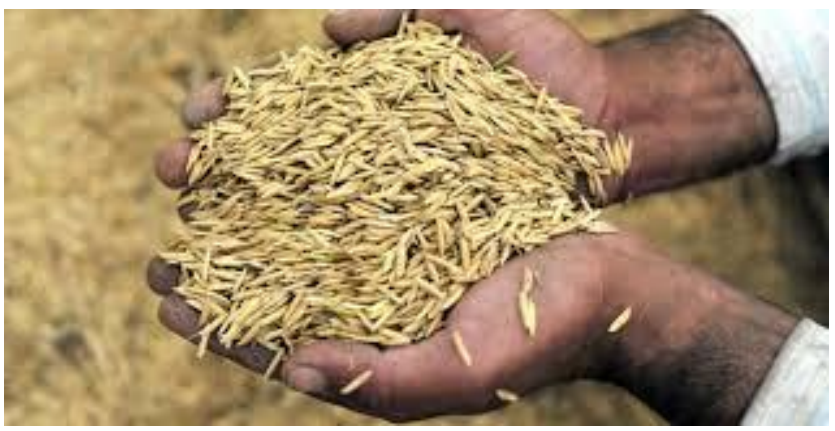


Fig.4 Saw dust

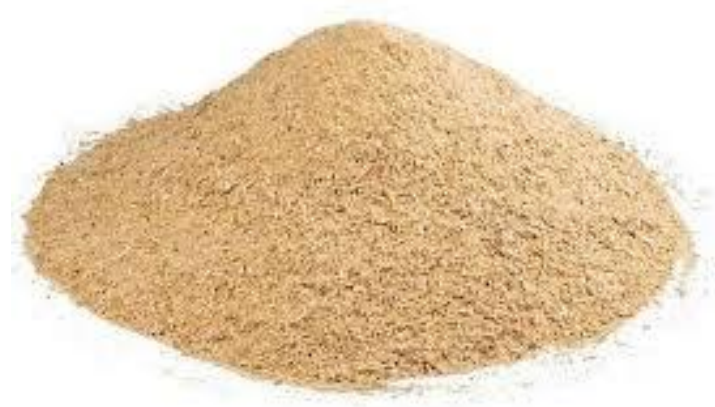

Fig.5 Cow dung

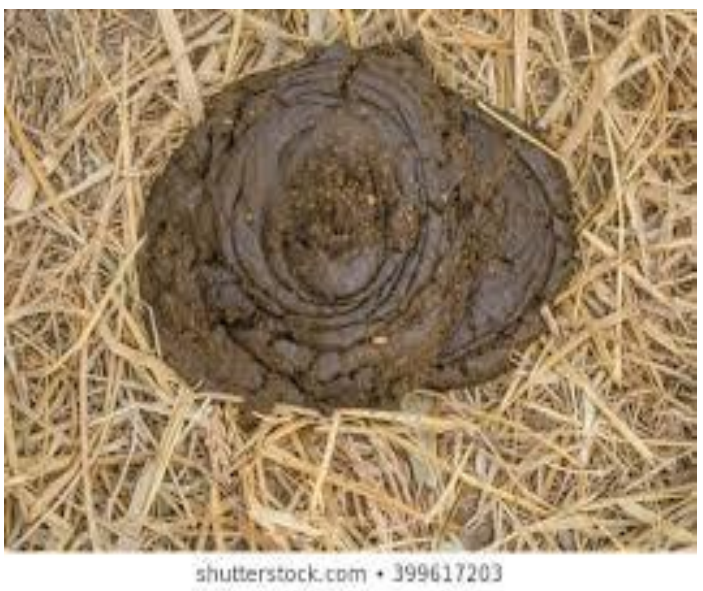

Fig.6 Hot air oven

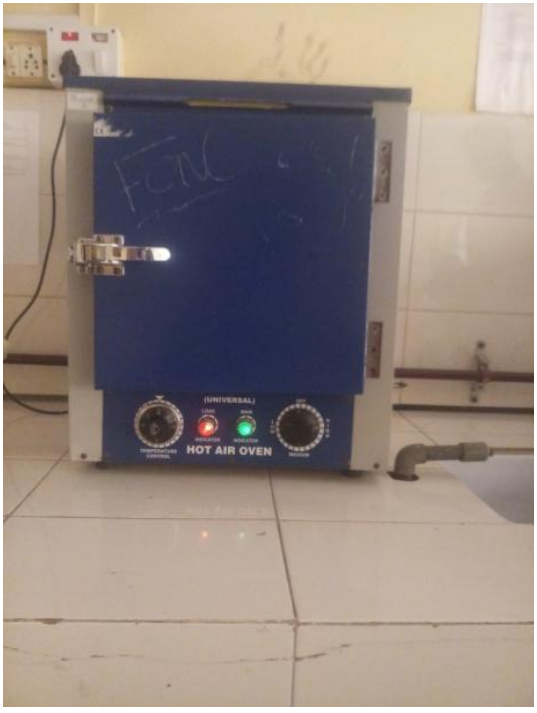


Fig.7 Muffle furnace

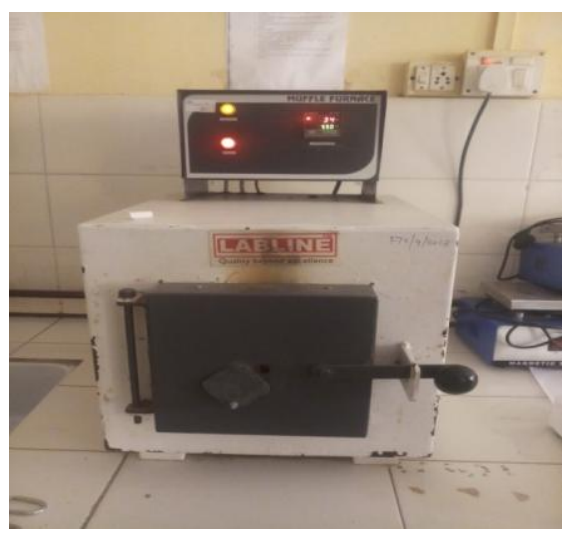

Fig.8 Proximate analysis of briquettes

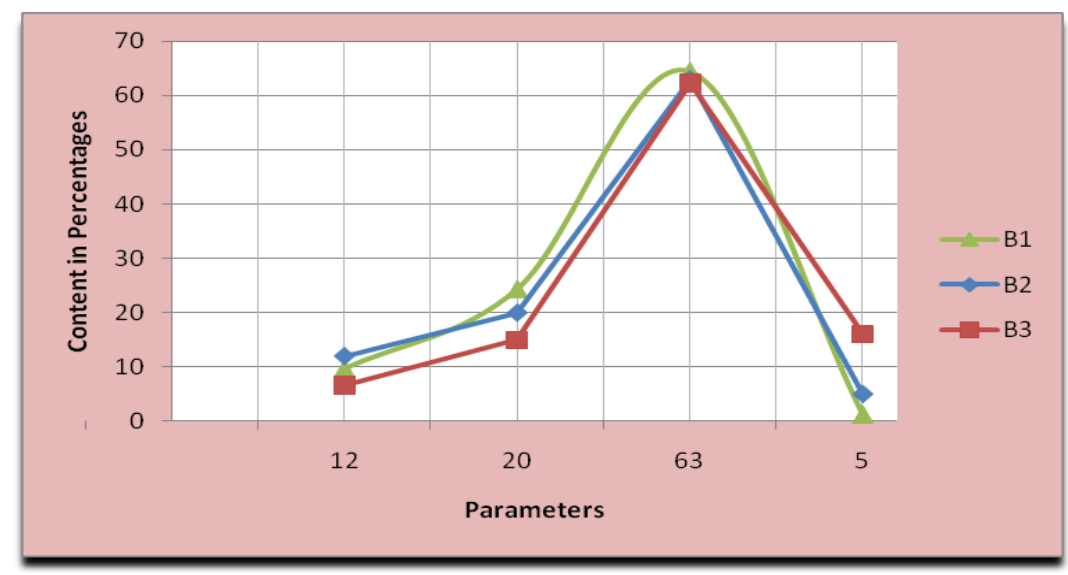

Fig.9 Ultimate analysis of briquettes

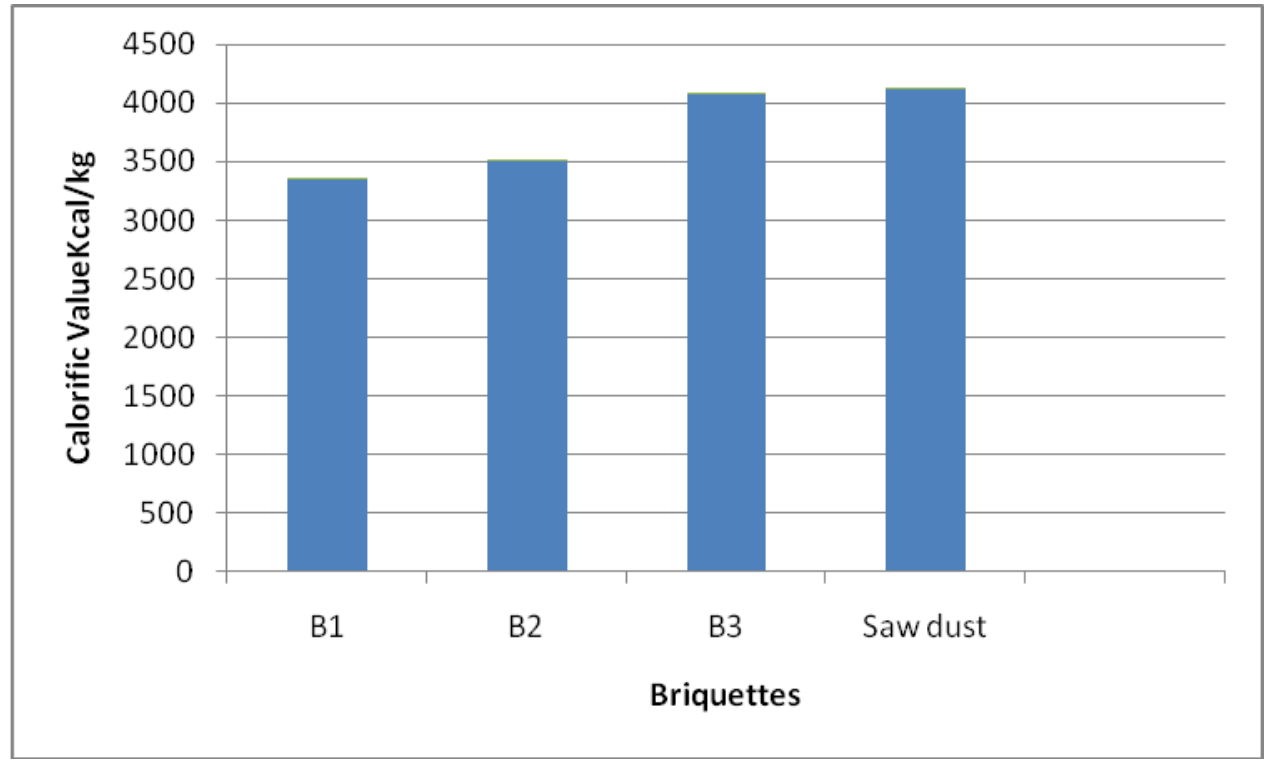


The highest monetary returns under higher irrigation regimes of 0.9 IW/CPE ratios through drip and weekly irrigations using check basin method along with higher nitrogen doses might be due to increased kernel and stover yields under favourable moisture conditions coupled with ample supply of nitrogen. The lowest monetary returns were noticed in drip irrigation at 0.7 IW/ CPE ratio along with $160 \mathrm{~kg} \mathrm{~N} \mathrm{ha}{ }^{-1}$, which might be due to reduced yields. Present investigations confirmed the results of Pennaiah (2005).

Remunerative returns obtained with the greengram-maize cropping system along with crop residue incorporation, were found to be more than with no residue incorporation (Fig. 9).

It is useful in determining the quantity of air required for combustion rate and the volume and combustion gases. The composition of the briquette analysis on an as - received basis showed B1 briquette $43.26 \%$ carbon, $5.2 \%$ hydrogen, $32.72 \%$ oxygen, $2.16 \%$ nitrogen, and $0.43 \%$ sulphur, and B2 briquette $46.46 \%$ carbon, $5.6 \%$ hydrogen, $30.3 \%$ oxygen, $2.27 \%$ nitrogen, and $0.56 \%$ sulphur,

And B3 briquette $49.86 \%$ carbon, $5.72 \%$ hydrogen, $33.16 \%$ oxygen, $1.31 \%$ nitrogen and $0.39 \%$ sulphur. The results agree with the observation made by Chaney (2010) who reported that analysis of biomass using the gas analysis procedure reveled the principle constituents as carbon, which comprises between $30 \%$ to $60 \%$ of the dry matter and typically $30 \%$ to $40 \%$ oxygen. Hydrogen, being the third main constituent, makes up between about 5\% and 6\% and nitrogen and sulphur normally makes up less than $1 \%$ of dry biomass.

Fossil based technology is the primary source in India that meets the energy requirement in small as well as large industrial applications.
Briquetting is a technology for densification of agricultural residues or wastes to increase their bulk density reduce their moisture and make briquettes of uniform sizes and shapes for easy handling, transport and storage. Briquettes can be defined as a product formed from physicmechanical conversion of loose and tiny particle size materials with or without binder in different shapes and sizes. Rice straw produced in large quantity as a byproduct of crop production can be converted into high quantity and durable soil fuel briquette that will be suitable for both domestic and industrial energy production.

The hand operated machine can be used to produce low density briquette which can use as domestic fuel in local stove and for industrial purpose. The heating value calculated at the optimum biomass binder ratio were sufficient to produce heat required for household cooking in rural communities and small scale industrial application like furnace and boiler.

\section{Suggestions for further work}

There is vast scope of further research and enhanced in this study: Following are some guideline by implementing which the study can be further carried out

Various types of blends can be used for further research like biomass blends with saw dust, saw dust blends, with mustard husk, and blends of biomass, mustard husk with and rice husk.

Various types of binder can be used for further research because of starch is very costly and other binder like commercially available adhesive are not good binder. They are costly also.

Determine the heating value and combustion properties of briquettes produced by the machine for other agricultural biomass. 
Work can be carried out on reducing moisture content in biomass briquette because it reduce the heating value of briquette.

\section{References}

Bellinger, P. L. and McColly, $\mathrm{H}$. (1961).Energy Requirements for Forming Hay Pellets. Agricultural Engineering. Vol. 42 (5,6):180

Bhattacharya, S.C. (1989), State of the Art of Biomass Densification. Division of Energy Technology. Energy Sources, N. Y., Taylor and Francis. Vol. 11 (3):161-186.

Bhattacharya, S. C. Albino, D. O. and Khaing, A. M. (2002). Effects of selected parameters on Performance and emission of biomass-fired cook stoves. Biomass and Bioenergy. Vol. 23: 387-395.

Bhattacharya, S. C. (2003). Commercialization options for biomass energy technologies ESCAP countries. International Journal of Energy Technology and Policy. Vol.1: 363 - 399.

Choudhury S.K hand book of Workshop Technology second edition.

Rathod, N.S., N.L. Palwar, A.K. Kurchania hand book of renewable energy theory and practices. Non-Convectional energy sources by J.D. Rai.

M.Madhava, B.V.S. Prasad, K.R. Ramesh (2011) Performance evolution of a hand operated compression type briquetting machine.

Priti P Lad, Bhagyashree N. Patil, and Suchita V Gupta (2014) Carbonation of Marketing Nut Shell.

\section{How to cite this article:}

Nitesh A. Pachpor, Priti P. Lad, Ganesh S. Bhatane, Saurabh S. Bajare and Ramesh J. Pilghar. 2019. Analysis of Paddy straw, Paddy Husk and Saw Dust Briquettes by using Hand Operated Briquetting Machine. Int.J.Curr.Microbiol.App.Sci. 8(11): 640-651.

doi: https://doi.org/10.20546/ijcmas.2019.811.077 